\title{
Insulin expressing cells from differentiated embryonic stem cells are not beta cells
}

\author{
S. Sipione ${ }^{1}$ A. Eshpeter ${ }^{2}$ J. G. Lyon ${ }^{2}$ G. S. Korbutt ${ }^{2}$ R. C. Bleackley ${ }^{1}$ \\ ${ }^{1}$ Department of Biochemistry, 460 Medical Sciences Building, University of Alberta, Edmonton, AB, Canada \\ ${ }^{2}$ Department of Surgery, University of Alberta, Edmonton, Alberta, Canada
}

\section{Abstract}

Aim/hypothesis. Embryonic stem (ES) cells have been proposed as a potential source of tissue for transplantation for the treatment of Type 1 diabetes. However, studies showing differentiation of beta cells from ES cells are controversial. The aim of this study was to characterise the insulin-expressing cells differentiated in vitro from ES cells and to assess their suitability for the treatment of diabetes.

Methods. ES cell-derived insulin-expressing cells were characterised by means of immunocytochemistry, RT-PCR and functional analyses. Activation of the Insulin I promoter during ES-cell differentiation was assessed in ES-cell lines transfected with a reporter gene. ES cell-derived cultures were transplanted into STZ-treated SCID-beige mice and blood glucose concentrations of diabetic mice were monitored for 3 weeks.

Results. Insulin-stained cells differentiated from ES cells were devoid of typical beta-cell granules, rarely showed immunoreactivity for C-peptide and were mostly apoptotic. The main producers of proinsulin/insulin in these cultures were neurons and neuronal precursors and a reporter gene under the control of the insulin I promoter was activated in cells with a neuronal phenotype. Insulin was released into the incubation medium but the secretion was not glucose-dependent. When the cultures were transplanted in diabetic mice they formed teratomas and did not reverse the hyperglycaemic state.

Conclusions/Interpretation. Our studies show that insulin-positive cells in vitro-differentiated from ES cells are not beta cells and suggest that alternative protocols, based on enrichment of ES cell-derived cultures with cells of the endodermal lineage, should be developed to generate true beta cells for the treatment of diabetes. [Diabetologia (2004) 47:499-508]

Keywords Type 1 diabetes - Embryonic stem cells · Islet neogenesis · Insulin · Pro-insulin · Nestin · Neuron precursors $\cdot$ Islet transplantation
Received: 11 August 2003 / Revised: 15 December 2003 Published online: 14 February 2004

(C) Springer-Verlag 2004

R. C. Bleackley $(\square)$

Department of Biochemistry, 460 Medical Sciences Building,

University of Alberta, Edmonton, AB, Canada T6G 2H7

E-mail: chris.bleackley@ualberta.ca

Abbreviations: ES, Embryonic stem - LIF, leukemia inhibitory factor $\cdot$ ITSF, insulin-transferrin-selenite-fibronectin

Bleackley and Korbutt laboratories contributed equally to this paper

\section{Introduction}

Diabetes mellitus affects millions of people worldwide. Whereas Type 2 diabetes is due to the development of insulin-resistance in peripheral tissues and progressive failure of beta cells to produce insulin, Type 1 diabetes results from autoimmunitary destruction of the beta cells. A significant advance in the search for the cure of Type 1 diabetes has been recently accomplished with the development of an islet transplant-protocol that successfully achieves insulin independence in Type 1 diabetic patients [1]. Unfortunately, the scarce availability of donor tissue limits the applicability of this therapy. To overcome this prob- 
lem researchers have focused on the development of possible alternative sources of transplantable tissue.

Embryonic stem (ES) cells have been proposed as a potential source of islet tissue since they can differentiate in vitro into several different cell types $[2,3,4,5$, $6,7]$. Enthusiasm was raised in the scientific community with a report that ES cells could differentiate into pancreatic islet-like structures [8]. The authors of that study had noticed that, although originating from a different germ layer, the development of the pancreas shared similarities with the development of the nervous system [9, 10, 11]. Therefore, they adapted a strategy used to generate neurons [6] to derive endocrine pancreatic cells from ES cells. This protocol involved sequential in vitro differentiation steps during which cultures were highly enriched in cells expressing nestin, an intermediate filament present in neural stem cells [12], but also expressed in a small population of pancreatic cells that have been proposed as possible islet precursors $[13,14]$. The nestin-positive cells were further differentiated into structures morphologically resembling pancreatic islets, connected to each other by a web of neurons, with insulinexpressing cells localised inside these structures and glucagon-positive cells at the periphery. The only caveat of this system seemed to be the low cellular insulin content of the beta cells and the failure of the islet-like structures to correct hyperglycaemia in diabetic mice.

Two other studies have been recently published with suggestions on conditions that would improve the original protocol, leading to the production of insulin-positive cells able to rescue streptozotocyn-treated animals $[15,16]$. More recently, however, it has been shown that insulin immunoreactivity in ES cell cultures may be due to insulin uptake from the medium, rather than insulin production [17]. In this study, contrary to previous reports, no message for insulin was detectable in culture. Therefore, it is now a matter of controversy whether true pancreatic beta cells can be differentiated from ES cells with the protocols so far developed.

We reproduced the original protocol for the differentiation of islet-like structures and further characterised the system and its potential suitability for the reversion of a diabetic condition. Our results support and complement previous observations [17] and clarify the controversy of differentiation of ES cells into pancreatic islets.

\section{Materials and methods}

Cell culture and in vitro differentiation of ES cells. Three mouse ES cell lines, AB1, D388 and J1, maintained on irradiated embryonic fibroblasts were used in the experiments. Differentiation into insulin-positive cells was done according to [8] with slight modification. Briefly, ES cells were grown in the absence of feeder layer on gelatin-coated dishes for two passages (Stage 1). Embryoid bodies were grown in suspension for 4 days in the absence of LIF (Stage 2), then transferred to gelatin-coated tissue culture dishes and incubated for 7 to 8 days in serum-free ITSF medium [6] (Stage 3). Cultures were then trypsinized and passed onto poly-ornithine/laminin coated dishes or coverslips, and grown in N2 medium supplemented with B27 (GIBCO, Grand Island, N.Y., USA), $20 \mu \mathrm{g} / \mathrm{ml}$ insulin, $1 \mu \mathrm{g} / \mathrm{ml}$ laminin (Sigma Chemical, St. Louis, Mo., USA), $10 \mu \mathrm{g} / \mathrm{ml} \mathrm{bFGF} \mathrm{and} 10 \mu \mathrm{g} / \mathrm{ml}$ EGF (R\&D Systems, Minneapolis, Minn., USA) (Stage 4). After 7 days bFGF and EGF were withdrawn and $10 \mathrm{mmol} / 1$ nicotinamide (Sigma Chemical) was added to the medium for the next 7 days (Stage 5).

Generation of ES cell lines stably expressing EGFP driven by the Insulin promoter. J1 cells were transfected with the plasmid -410rINS1-d2EGFP (a kind gift from Dr. T. Kieffer, UBC) [18]. The transgenic promoter comprised $410 \mathrm{bp}$ upstream of the transcriptional initiation site of the Insulin I gene and thus included all of the positive regulatory cis-acting elements of murine insulin I promoter [19]. Cell transfection was done using Lipofectamine (Invitrogen, Carlsbad, Calif., USA) according to the manufacturer's instructions. pcDNA3.1 vector (Invitrogen) was co-transfected for neomycin selection of recombinant clones. Resistant clones were screened for genome integration of the rat Insulin I promoter and d2EGFP cDNA by genomic PCR. Positive clones were isolated and differentiated using the protocol described above. Two different clones (J1/I5 and J1/I11), in which EGFP expression was activated as a result of the differentiation procedure, were used in the experiments.

Immunocytochemistry. Cells grown on coverslips were fixed in $4 \%$ paraformaldehyde in PBS for $45 \mathrm{~min}$ at $4^{\circ} \mathrm{C}$. Non-specific binding-sites were blocked with $4 \%$ goat serum in PBS for $1 \mathrm{~h}$ at room temperature. Incubations with the primary and secondary antibodies were done for $1 \mathrm{~h}$ at room temperature. The following primary antibodies were used: guinea pig anti-insulin (1:1000, Dako, Carpinteria, Calif., USA), mouse anti-glucagon (1:7500, Sigma), mouse anti-nestin (1:200, BD Pharmingen, San Diego, Calif., USA), mouse anti- $\$ 3$ tubulin (1:150, Chemicon, Temecula, Calif., USA), mouse anti-GAP43 (1:500, Sigma), rabbit anti-synaptophysin (1:100, Dako) and rabbit anti-C-Peptide (1:100, Linco, St. Charles, Mo., USA). Secondary antibodies were: anti-guinea pig Alexa 488 and Alexa 594, goat anti-rabbit Alexa 488, goat anti-rabbit Alexa 546 (1:1000, Molecular Probes, Eugene, Ore., USA), and goat anti-mouse Texas Red (1:200, Caltag Laboratories, Burlingame, Calif., USA). TUNEL reaction (Boehringher Mannheim, Mannheim, Germany) was done according to the manufacturer's instructions.

$R T-P C R$. Total RNA was extracted using RNeasy Mini Kit (Qiagen, Mississauga, Ont., Canada). RNA samples were digested with DNaseI (Invitrogen) and retrotranscribed with SuperScript II (Invitrogen) following the manufacturer's instructions.

PCR was done with HiFi Taq polymerase (Invitrogen) according to the manufacturer's instructions for 30 cycles (40 cycles for pancreatic polypeptide).

Insulin secretory activity and hormone content. Stage 5 cultures were pre-incubated overnight in regular or in insulin-free medium. Duplicate aliquots of cells were incubated in medium containing $2.8 \mathrm{mmol} / 1$ or $20 \mathrm{mmol} / 1$ glucose for $2 \mathrm{~h}$ at $37^{\circ} \mathrm{C}$. Insulin secretion into the incubation medium was assessed 
with an insulin radioimmunoassay (RIA) kit (Linco). Cellular insulin content was assessed after extraction in $2 \mathrm{mmol} / \mathrm{l}$ acetic acid containing $0.25 \%$ BSA. A $p$ value of less than 0.05 was considered statistically significant.

Transplantation in diabetic mice. Stage 5 cultures were transplanted under the left kidney capsule of streptozotocin (250 mg/kg) induced-diabetic SCID-beige mice (Jackson Laboratories/Harbor, Me., USA). Twelve mice (all 6-8 week-old males) were implanted in two independent experiments. Aliquots consisting of approximately 4 million cells were aspirated into polyethylene tubing, pelleted by centrifugation, and gently placed under the kidney capsule with the aid of a micromanipulator syringe. Mice were subsequently monitored twice a week for blood glucose values. All animal experimental procedures were carried out according to the guidelines of the Canadian Council on Animal Care.

\section{Results}

Clusters of insulin-positive cells derived from ES cells. To differentiate ES cells into insulin-expressing cells we used a multi-step protocol described previously [8]. When embryoid bodies (Stage 2) were plated onto gelatin and grown in ITSF medium (Stage 3), microscopic analyses of the cultures showed the presence of pulsating cardiomyocites, fibroblast-like cells, endothelial and other cell types. The number of nestin-positive cells, however, was relatively constant accounting for about $25 \%$ of the cells in culture. When these cultures were dissociated and re-plated onto poly-ornithine/laminin-coated dishes for further differentiation (Stage 4), terminally differentiated cells did not attach and nestin-positive cells became the most represented cell type (up to $80 \%$ of the Stage 4 cultures). Dense clusters of cells appeared after 7 to 8 days in Stage 4 medium and during Stage 5 (Fig. 1A). Insulin staining was already present at the end of Stage 4, with groups of insulin-positive cells usually surrounded by nestin-expressing cells (Fig. 1B). By the end of Stage 5 most of the nestin staining disappeared and clusters of insulin-positive cells were often associated with neurons, which represented a large part of the cultures at this stage (Fig. 1C). Upon enzymatic dissociation of the cultures $44 \%$ of the cells were synaptophysin-positive and $14 \%$ insulin-positive. The insulin-positive cells were often reduced in size, with small nuclei and frequent signs of apoptosis, as shown by TUNEL staining (Fig. 1D). No insulin granules-a distinctive feature of beta cells, were observed with electron microscopy.

Proinsulin is synthesized in nestin-positive precursors and neurons. Although the cells that stained for insulin did not usually stain for neuronal markers such as $\beta$ III-tubulin or synaptophysin, a distinct punctated insulin staining was observed in some neuronal axons (Fig. 1E-G) and in the cytoplasm of synaptophysinexpressing cells (Fig. 1H-J).
To specifically address the presence of endogenously produced insulin in our cultures we used an antibody against $\mathrm{C}$-peptide. This antibody recognises the mature C-peptide and proinsulin, but not insulin. Since only the mature form of insulin is added to the medium, immunoreactivity for C-peptide/proinsulin would indicate that the precursor proinsulin is synthetised by cells in culture. Immunoreactivity for $\mathrm{C}$-peptide was indeed present in our cultures. Unexpectedly, in most cases the anti-C-peptide/proinsulin and the anti-insulin antibodies (the latter one not recognising the precursor proinsulin) stained different populations of cells (Fig. 2A,C), the C-peptide/proinsulin staining being localised in nestin-positive (Fig. 2B) and neuron-like cells and along axonal processes (Fig. 2B,D). Only a minor fraction of cells showed co-expression of C-peptide/proinsulin and mature insulin, and even in these cases the mature hormone was often present in a different subcellular compartment than the C-peptide/proinsulin (Fig. 2E-I). We did not observe staining for glucagon in our cultures, although we saw expression of glucagon mRNA by RT-PCR in isolated experiments.

ES-derived cultures express insulin mRNA and transcription factors associated with pancreatic and neuronal development. RT-PCR analysis was done on cultures at different stages during the differentiation procedure. We found that transcription factors that are known to be involved in pancreas and nervous system development were expressed at early stages of differentiation (Fig. 3). No PP mRNA was detectable at any stage.

In rodents there are two non-allelic insulin genes, Insulin $I$ and $I I$, both expressed and regulated in beta cells [19]. In our cultures the Insulin II mRNA was always detectable. We rarely observed Glucagon and Insulin I mRNA; however, in most of the cultures the mRNAs for these genes were undetectable.

Transgenic Insulin I gene promoter is activated early in cells resembling neurons. To facilitate identification and analysis of the insulin-positive cells that differentiate from ES cells, we generated stable ES-cell clones expressing the enhanced green fluorescent protein (d2EGFP) under control of the rat Insulin I promoter.

Upon differentiation, the transgenic clones formed clusters of cells exactly as described above for the parental non-transfected ES cells. FACS analysis performed during the in vitro differentiation showed that the first EGFP-expressing cells appeared during Stage $2(0.045 \pm 0.035 \%$ of the viable cells), increased progressively in number through Stage $3(0.73 \pm 0.39 \%)$ and Stage $4(0.9 \pm 0.4 \%)$ and then decreased at Stage 5 $(0.063 \pm 0.059 \%)$.

EGFP-positive cells differentiated inside adherent spherical structures formed by the proliferation of nestin-positive precursors. The cells strongly resembled 

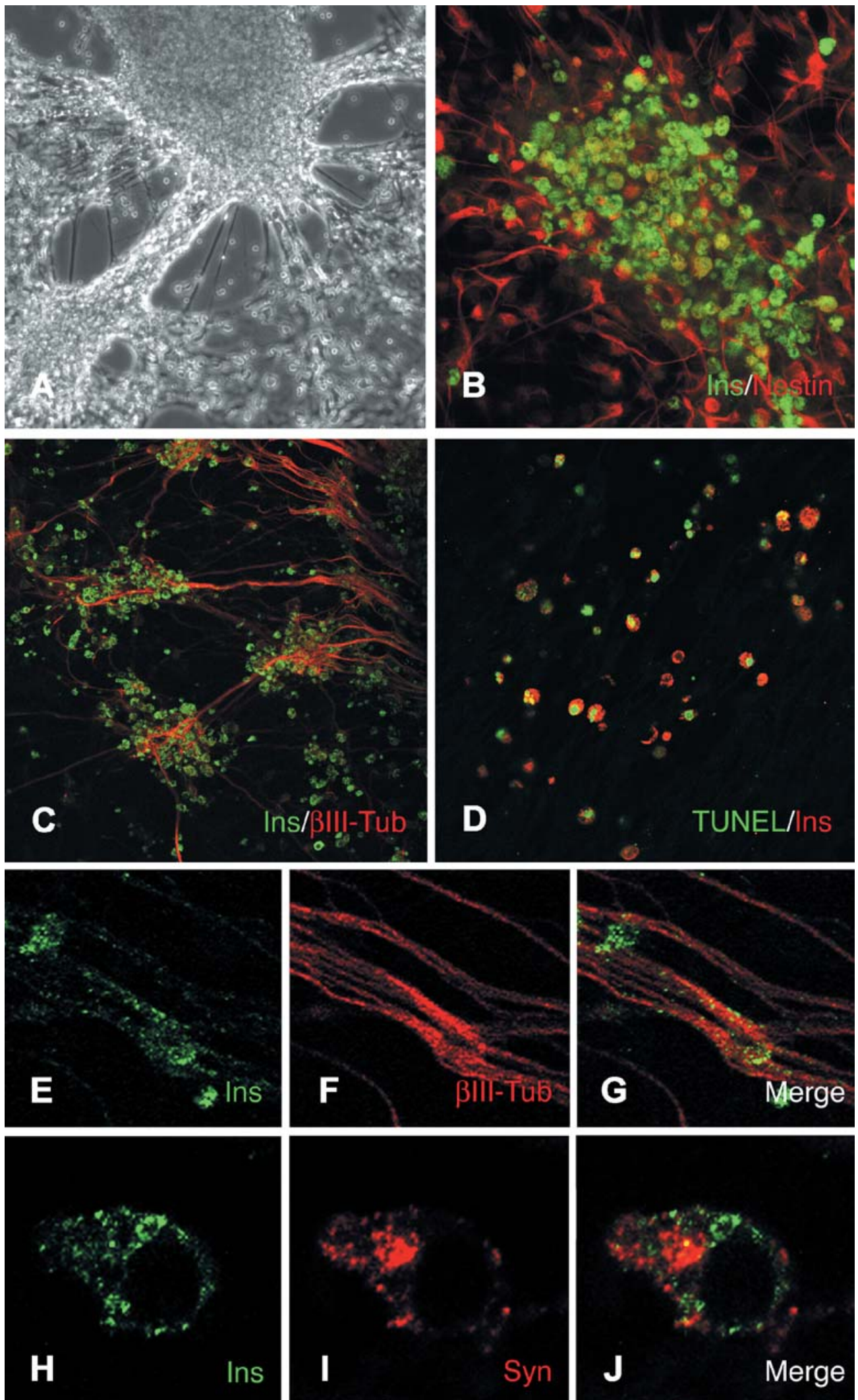

Fig. 1A-J. Differentiation of insulin-positive cells at Stage 4 and 5. (A) Phase Contrast image of cultures at the end of Stage 4. (B-J) Confocal immunofluorescence microscopy. (B) Immunostaining for insulin and nestin at the end of Stage 4. (C) Stage 5. Bundles of axons connecting neurons and insulin-positive cell clusters. (D) Stage 5. TUNEL staining. (E-G) Stage 5. Neuronal

axons stained for insulin and $\beta$ III-Tubulin. A punctuated insulin staining is visible along the axons. (H-J) Stage 5. Co-expression of insulin and synaptophysin (Syn) in a neuroendocrine cell. The images shown are representative of three independent experiments. Ins, insulin; $\beta$ III-tub, $\beta$ III-tubulin; Syn, synaptophysin 

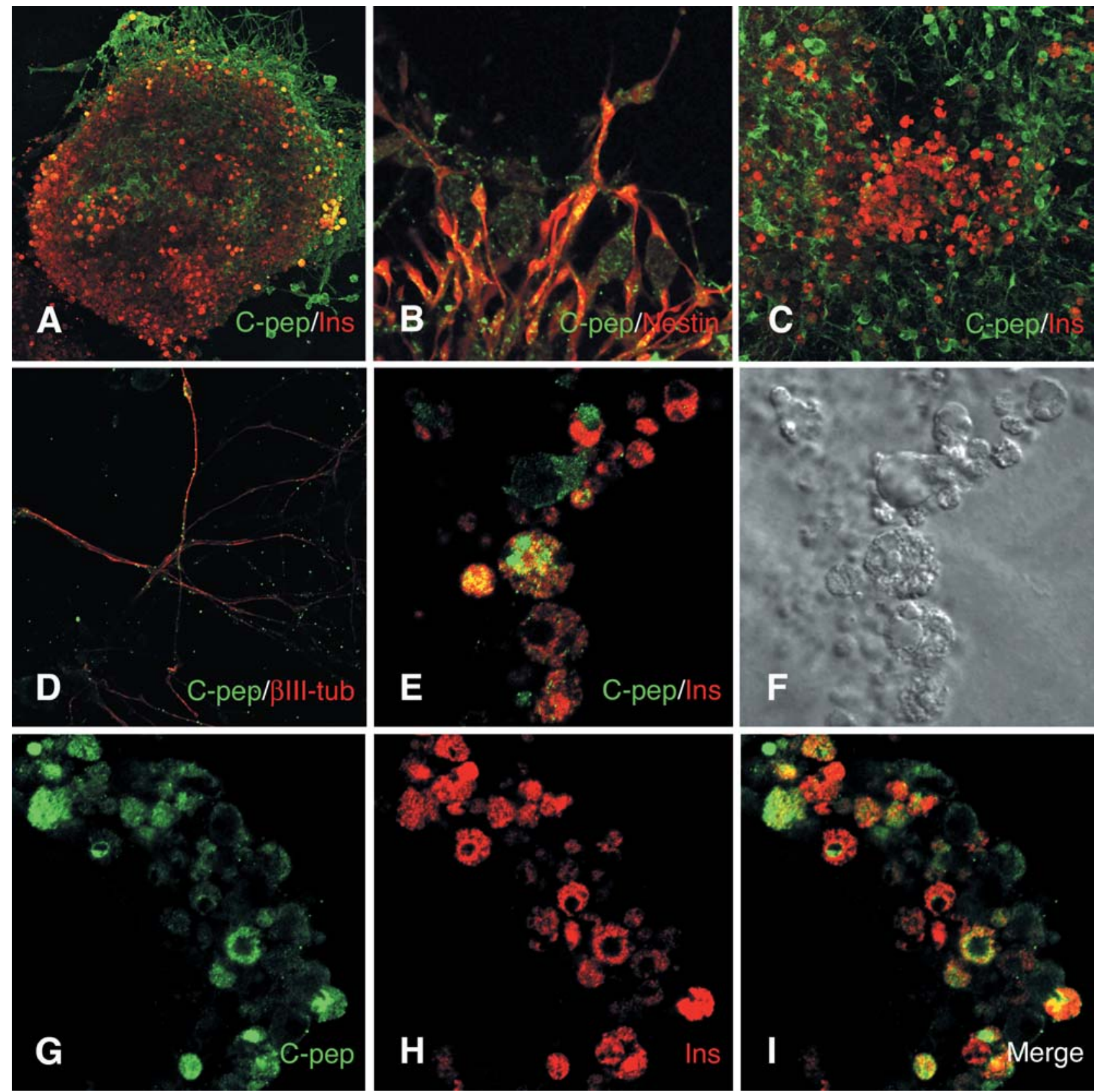

Fig. 2A-I. Expression of C-peptide/proinsulin in Stage 4 and Stage 5 cultures. Confocal images. (A) Stage 4. Sphere-like structure developed from proliferation of nestin-positive cells. (B) Stage 4. C-peptide/proinsulin co-localisation with nestin. (C) Stage 5. C-peptide/proinsulin localisation in neuron-like cells surrounding clusters of insulin-positive cells. (D) Stage 5. Neuronal axons stained with $\beta$ III-tubulin show punctuated C-peptide/proinsulin staining. (E) Stage 5. Insulin-positive cells showing C-peptide/proinsulin immunoreactivity. (F) DIC image of (E) showing necrotic/apoptotic features of most of the insulin-positive cells. (G-I) Stage 4. Distribution of C-peptide/proinsulin and insulin staining in a small cluster of insulin-positive cells. The images shown are representative of three independent experiments. Ins, insulin; C-pep, C-peptide/proinsulin; $\beta$ III-tub, $\beta$ III-tubulin

neurons (Fig. 4A). When we stained the cultures with antibodies against the neural-specific Growth-Associated Protein-43 (GAP-43), we found that, although GAP43 and EGFP were expressed in two largely distinct cell populations, few cells co-expressed both (Fig. 4B).

Immunocytochemistry of the cultures at Stage 4 and Stage 5 showed that no insulin-positive cells expressed EGFP and no EGFP-expressing cells stained for mature insulin (Fig. 4C). However, when we used the antibody against the C-peptide/proinsulin we occasionally observed cells with double labelling (Fig. 4D).

RT-PCR analysis performed on FACS-sorted EGFP-positive cells showed that the endogenous Insulin I gene was not expressed in these cells, despite the activation of the transgenic insulin I promoter, neither was $P d x l$. 

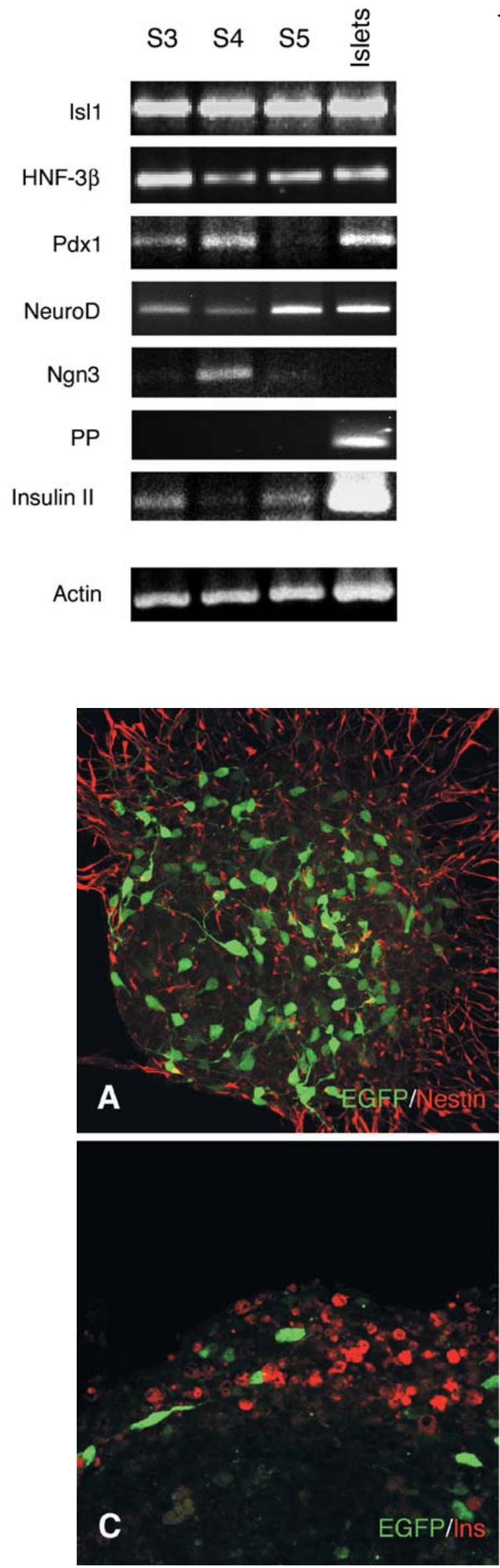

4 Fig. 3. RT-PCR analysis of ES cell-derived cultures. S3, Stage 3; S4, Stage 4; S5, Stage 5. Results were reproduced in three independent ES-cell lines

Insulin secretory activity is not glucose-dependent. An essential feature of pancreatic beta cells is the ability to release insulin in response to high glucose concentration. Although the ES cell-derived cultures did secrete insulin into the medium, the cells did not exhibit an increased secretory activity in response to glucose (Fig. 5A). Identical results were obtained when the assay was done with sorted $\mathrm{EGFP}^{+}$and $\mathrm{EGFP}^{-}$cells. Since it has been proposed that insulin can be taken up from the medium and then released by dying cells

Fig. 4A-D. Activation of the reporter gene EGFP in Stage 4 and Stage 5 cultures. Confocal microscopy images. (A) Stage 4. Differentiation of neuron-like EGFP-positive cells inside spheres of nestin precursors. (B) Stage 5. Co-localisation of EGFP and the neuronal marker GAP43. (C) Stage 5. Insulin staining do not co-localise with EGFP expression. (D) Colocalisation of EGFP and C-peptide/proinsulin. The images shown are representative of three independent experiments. Ins, insulin; C-pep, C-peptide/proinsulin
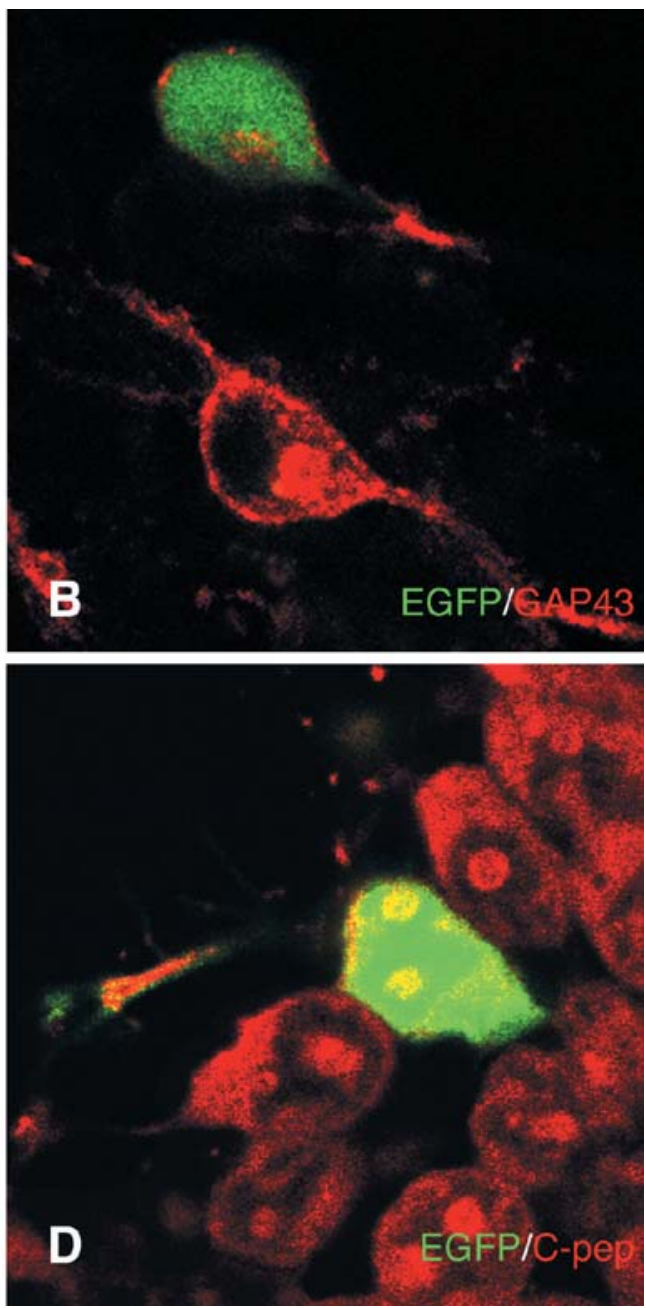
A

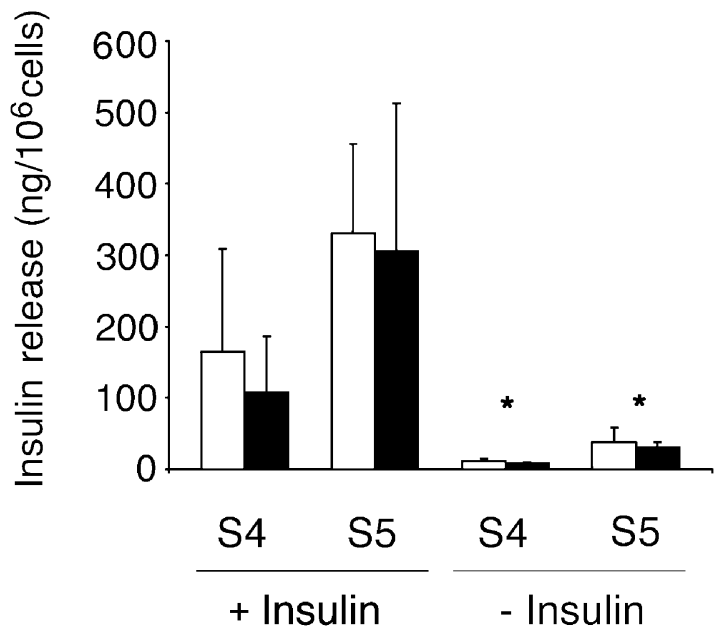

B

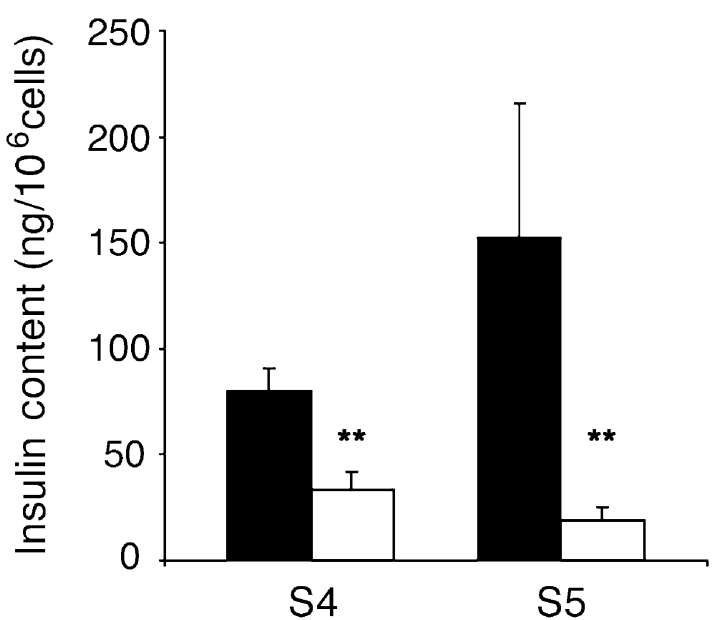

Fig. 5. (A) Insulin secretory activity. Cultures at Stage 4 (S4) and Stage 5 (S5) were pre-incubated overnight with medium with $25 \mu \mathrm{mol} / \mathrm{l}$ insulin (+ Insulin) or no insulin ( - Insulin). The day after cells were incubated for $2 \mathrm{~h}$ in medium containing low $(2.8 \mathrm{mmol} / \mathrm{l})$ or high $(20 \mathrm{mmol} / \mathrm{l})$ glucose concentration. RIA for insulin was done on the incubation medium. White bars $2.8 \mathrm{mmol} / \mathrm{l}$ glucose; black bars $20 \mathrm{mmol} / \mathrm{l}$ glucose. Data represent the mean $\pm \mathrm{SD}$ of three independent experiments done on three different ES-cell clones. (B) Intracellular insulin content. Cells were pre-incubated overnight as described in A. Intracellular insulin content was measured by RIA. Black bars, overnight pre-incubation with $25 \mu \mathrm{mol} / 1$ insulin; white bars, overnight pre-incubation in insulin-free medium. Data represent the mean \pm SD of a total of four values $(n=4)$ per group using two different ES-cell clones. Results were normalised to the number of cells in each sample, calculated on the basis of the DNA content and assuming a mouse DNA content of $6 \mathrm{pg} / \mathrm{cell}$. Statistical significance was determined by two-tailed Student's $t$ test. ${ }^{*} p<0.05 ; * * p<0.006$
[17], we pre-incubated the cultures for $18 \mathrm{~h}$ in medium with $(25 \mu \mathrm{mol} / \mathrm{l}$ insulin, i.e. the concentration routinely added to the differentiation medium) or without insulin, before the insulin-release assay. Cultures preincubated in insulin-free medium not only secreted less insulin ( $p<0.05$, Fig. 5A), but also their intracellular insulin content was reduced (Fig. 5B). For comparison with normal islets, a mouse beta cell contains an average of $30 \mathrm{pg}$ of insulin, 6 to $8 \%$ of which is released over $2 \mathrm{~h}$ of incubation in high-glucose medium (accounting for an average release of $2 \mu \mathrm{g}$ of insulin $/ 10^{6}$ cells). In the absence of insulin in the pre-incubation medium, the ES cell-derived cultures contained 1000 -fold less insulin than a mouse beta cell and since the insulin secreted over $2 \mathrm{~h}$ was approximately the same of the intracellular content, our data suggest that insulin was secreted through a constitutive pathway.

Transplantation does not correct diabetes in SCID mice. After streptozotocin administration, all mice had blood glucose concentrations above $20 \mathrm{mmol} / \mathrm{l}$. However, all animals implanted with stage 5 derived cells did not show any reduction in blood glucose. Due to the prolonged hyperglycaemia and poor health of the animals, mice were killed between 15 to 25 days posttransplant. When the grafts were examined histologically, no insulin or Pdx1 positive cells were observed and the morphology of the graft resembled a teratoma.

\section{Discussion}

Recently several studies have reported the ability to differentiate insulin-positive cells and pancreatic isletlike structures from ES cells $[8,15,16]$. The production of insulin-expressing cells in these studies, however, has been questioned since using the same differentiation protocol, it was shown that insulin immunoreactivity was due to insulin uptake from the medium rather than endogenous synthesis of the hormone [17]. It is not yet clear whether this phenomenon could have been responsible for all the insulin immunoreactivity observed in the previous studies. Whereas in that study no insulin mRNA was detectable [17], in the other studies insulin expression was present $[8,15$, 16]. Therefore, in the absence of conclusive data regarding the nature of the cells that do express insulin message in culture, it is still controversial whether beta cells can be generated with Lumelsky's protocol.

In our experiments, the potential of ES cells to generate cells of the endoderm lineage and, consequently, pancreatic precursors was probably lost when the cultures were selectively enriched with cells expressing nestin [8]. This step had its original motivation in reports indicating pancreatic nestin-positive cells as potential precursors of islets $[13,14]$. In our cultures, up to $80 \%$ of the cells were nestin-positive after selective enrichment. Insulin-positive cells differentiated into 
clusters of nestin cells. However, recent studies have strongly argued against a role of nestin-expressing cells in the development of the pancreas and, consequently, against the possibility that true beta cells might be derived in vitro from nestin-expressing precursors [21, 22, 23, 24, 25, 26].

In the ES cell-derived cultures we observed expression of transcription factors involved in the development of the pancreas $[8,27,28]$. We also detected expression of Pdx1, a key player in pancreas ontogenesis [29] and mature beta-cell physiology [30], expression of which had been elusive in previous studies. Similar data had suggested in the past, that a program of pancreatic differentiation had been activated in culture [8]. However, the same transcription factors appear to be involved in the development of the nervous system $[31,32]$. Pdx 1 has been shown to be expressed in neural precursors in different embryonic brain regions [33] and Ngn3, transiently expressed in the spinal cord and hypothalamus, seems to be involved in the development of specific types of interneurons and in the process of glia differentiation $[34,35]$. Since our cultures were highly enriched in neurons and neuronal precursors, we believe that expression of those transcription factors occurred in cells of the neural lineage. This hypothesis is supported by the fact that, while in islet progenitors the transcription factor Ngn3 as well as pancreatic polypeptide are transiently expressed [36, 37], in our cultures only Ngn3 was expressed.

In contrast to a previous report [17] we did observe expression of insulin mRNA in the cultures, along with synthesis of the insulin precursor. Indeed, a considerable number of cells showed immunoreactivity when stained with an antibody against C-peptide/proinsulin. Unexpectedly, however, the majority of the immunoreactivity was localised in neurons and nestinpositive cells. Insulin expression in neuronal cultures and in the nervous system has been reported (reviewed in [38]), leading to the hypothesis that insulin could have a role during the development of the nervous system [39, 40, 41, 42].

In pancreatic beta cells $\mathrm{C}$-peptide and mature insulin are present in equimolar ratios and co-localise in the secretory granules $[20,43]$. In our cultures the C-peptide/proinsulin immunoreactivity was largely distinct from that of insulin, with co-expression limited to a small subset of the insulin-positive cells. Even in the case in which both C-peptide/proinsulin and insulin immunoreactivity were present in the same cells, the subcellular distribution was only partially overlapping. Since the anti-C-peptide antibody used in this study cross-reacts with both mature C-peptide and proinsulin (but not with mature insulin), we could not assess which molecular species was responsible for the observed immunostaining. However, since the majority of C-peptide-positive cells did not stain for mature insulin we speculate that the immunoreactivity was due to unprocessed proinsulin. Our hypothesis is supported by studies showing that in the developing nervous system (or at least in specific areas of it), the majority of proinsulin is not processed to the mature form $[44,45,46]$.

On the other hand, the majority of insulin-positive cells that were not reactive to the $\mathrm{C}$-peptide/proinsulin antibody may have taken up insulin from the medium [17]. In addition, the majority of the insulin-positive cells showed signs of necrosis and/or apoptosis and, it is tempting to speculate that they could represent dying cells (nestin precursors, neurons or other cell types). Furthermore, stimulation with high glucose concentration did not significantly affect insulin secretion, indicating that a typical beta-cell response was absent. These observations, along with electron microscopy data showing absence of typical secretory granules, suggest that the insulin-positive cells developed in culture were not beta cells.

Data on insulin gene expression also supported the presence of proinsulin immunoreactivity mainly in cells of neuronal lineage. In our cultures only the Insulin II mRNA was consistently detectable, in agreement with reports showing preferential expression of the Insulin II gene during mouse brain development [41, 47].

A reporter gene (EGFP) under control of the Insulin I promoter was activated specifically in cells with striking morphological similarities to neurons. In a previous report [17], activation of similar reporter genes occurred only in one out of 100000 cells and these cells were not further characterised. In our study up to $1 \%$ of the cells turned on the transgene. Surprisingly, activation of the transgenic promoter in two different cell clones was not accompanied by expression of the endogenous Insulin I gene. The explanation for these apparently contradictory results may reside in the fact that the Insulin I gene contains a cis-acting silencer located between -4.0 and $-2.0 \mathrm{~kb}$ from the transcriptional start site [48] that was not included in the DNA construct used in this study. Since the same promoter region is commonly used for studies on regulation of insulin gene expression, our data caution against interpreting results based only on activation of a similar reporter gene. Of note, the EGFP-positive cells did not express Pdx1. Activation of insulin genes in the absence of this transcription factor was reported for a tumour of neuroectodermal origin [49] and in Pdx1-null mice [50].

Although the majority of EGFP-positive cells failed to demonstrate the presence of typical neuronal markers, some of them did express the neuron-specific protein GAP-43 [51]. Therefore, EGFP expression could have marked a brief transitional state in the process of neuronal differentiation in which a specific array of expressed transcription factors was able to activate the transgenic Insulin I promoter but not the endogenous one. 
When Stage 5 cultures were transplanted into mice in which diabetes had been induced by STZ treatment, hyperglycaemia persisted and no significant effect on the life-span of the animals was observed. The small amount of active hormone produced by the transplanted cells might not have been enough to reverse a severe hyperglycaemia. Alternatively, insulin production could have been further down-regulated upon transplantation, as suggested by the fact that no insulinpositive cells were detected in the grafts. Notably, the engrafted tissue consistently formed teratomas. Although these data are in contrast with previous studies reporting on extension of the animal lifespan [15] or normalisation of the glycaemia [16], the discrepancy may be due to differences in the procedure used for transplantation and in the severity of the diabetic state induced before transplantation.

In conclusion, we believe that our work, while supporting a previous report [17], provides answers to crucial issues that had been left unsolved. We demonstrate that the insulin-positive cells that differentiate from nestin-positive cells are not beta cells and, for the first time, that the majority of the cells that are responsible for the insulin expression in culture have neuronal features. Furthermore, we show that such cultures are not suitable for transplantation for the treatment of diabetes. What remains to be investigated is whether (pro)insulin-expressing neurons can be coaxed to produce and secrete insulin in a glucose-regulated manner. A recent study, showing that insulin-producing neurons are the major suppliers of systemic insulin for maintenance of glucose homeostasis in Drosophila [52], seems to suggest that such a scenario could be possible if evolution has not erased this ancient neuronal function.

Acknowledgements. We thank Dr. T. Kieffer and Dr. J. Seufert for providing us with the -410rINS1-d2EGFP plasmid. We also thank S. Pagliardini, Dr. X.J. Sun, Dr. I.S. Goping, G. Baron and C. Frantz for advice on confocal microscopy, Dr. E. Posse De Chaves and Dr. M. Michalak for helpful discussion. This work was supported by grants from the Canadian Institute of Health Research (CIHR), Stem Cell Network of Canada, Alberta Heritage Foundation for Medical Research (AHFMR) and the Juvenile Diabetes Research Foundation (JDRF). R.C. Bleackley is a CIHR Distinguished Scientist, a Medical Scientist of the AHFMR, a Howard Hughes International Scholar, and a Canada Research Chair. G.S. Korbutt is a recipient of a Senior Scholarship of the AHFMR and a Career Development Award from the JDRF. S. Sipione is supported by a postdoctoral research fellowship from AHFMR.

\section{References}

1. Shapiro AM, Lakey JR, Ryan EA et al. (2000) Islet transplantation in seven patients with type 1 diabetes mellitus using a glucocorticoid-free immunosuppressive regimen. N Engl J Med 343:230-238

2. Wiles MV, Keller G (1991) Multiple hematopoietic lineages develop from embryonic stem (ES) cells in culture. Development 111:259-267
3. Rohwedel J, Maltsev V, Bober E, Arnold HH, Hescheler J, Wobus AM (1994) Muscle cell differentiation of embryonic stem cells reflects myogenesis in vivo: developmentally regulated expression of myogenic determination genes and functional expression of ionic currents. Dev Biol 164:87-101

4. Wobus AM, Wallukat G, Hescheler J (1991) Pluripotent mouse embryonic stem cells are able to differentiate into cardiomyocytes expressing chronotropic responses to adrenergic and cholinergic agents and $\mathrm{Ca} 2+$ channel blockers. Differentiation 48:173-182

5. Dani C, Smith AG, Dessolin S et al. (1997) Differentiation of embryonic stem cells into adipocytes in vitro. J Cell Sci 110:1279-1285

6. Okabe S, Forsberg-Nilsson K, Spiro AC, Segal M, McKay RD (1996) Development of neuronal precursor cells and functional postmitotic neurons from embryonic stem cells in vitro. Mech Dev 59:89-102

7. Abe K, Niwa H, Iwase K et al. (1996) Endoderm-specific gene expression in embryonic stem cells differentiated to embryoid bodies. Exp Cell Res 229:27-34

8. Lumelsky N, Blondel O, Laeng P, Velasco I, Ravin R, McKay R (2001) Differentiation of embryonic stem cells to insulin-secreting structures similar to pancreatic islets. Science 292:1389-1394

9. Kim SK, Hebrok M, Melton DA (1997) Notochord to endoderm signaling is required for pancreas development. Development 124:4243-4252

10. Li H, Arber S, Jessell TM, Edlund H (1999) Selective agenesis of the dorsal pancreas in mice lacking homeobox gene Hlxb9. Nat Genet 23:67-70

11. Schwitzgebel VM, Scheel DW, Conners JR et al. (2000) Expression of neurogenin3 reveals an islet cell precursor population in the pancreas. Development 127:3533-3542

12. Lendahl U, Zimmerman LB, McKay RD (1990) CNS stem cells express a new class of intermediate filament protein. Cell 60:585-595

13. Hunziker E, Stein M (2000) Nestin-expressing cells in the pancreatic islets of Langerhans. Biochem Biophys Res Commun 271:116-119

14. Zulewski H, Abraham EJ, Gerlach MJ et al. (2001) Multipotential nestin-positive stem cells isolated from adult pancreatic islets differentiate ex vivo into pancreatic endocrine, exocrine, and hepatic phenotypes. Diabetes 50:521533

15. Hori Y, Rulifson IC, Tsai BC, Heit JJ, Cahoy JD, Kim SK (2002) Growth inhibitors promote differentiation of insulin-producing tissue from embryonic stem cells. Proc Natl Acad Sci USA 99:16105-16110

16. Blyszczuk P, Czyz J, Kania G et al. (2003) Expression of Pax4 in embryonic stem cells promotes differentiation of nestin-positive progenitor and insulin-producing cells. Proc Natl Acad Sci USA 100:998-1003

17. Rajagopal J, Anderson WJ, Kume S, Martinez OI, Melton DA (2003) Insulin staining of ES cell progeny from insulin uptake. Science 299:363

18. Seufert J, Kieffer TJ, Habener JF (1999) Leptin inhibits insulin gene transcription and reverses hyperinsulinemia in leptin-deficient ob/ob mice. Proc Natl Acad Sci USA 96:674-679

19. Melloul D, Marshak S, Cerasi E (2002) Regulation of insulin gene transcription. Diabetologia 45:309-326

20. Steiner DF, Cunningham D, Spigelman L, Aten B (1967) Insulin biosynthesis: evidence for a precursor. Science 157:697-700

21. Humphrey RK, Bucay N, Beattie GM et al. (2003) Characterization and isolation of promoter-defined nestin-positive cells from the human fetal pancreas. Diabetes 52:2519-2525 
22. Selander L, Edlund H (2002) Nestin is expressed in mesenchymal and not epithelial cells of the developing mouse pancreas. Mech Dev 113:189-192

23. Treutelaar MK, Skidmore JM, Dias-Leme CL et al. (2003) Nestin-lineage cells contribute to the microvasculature but not endocrine cells of the islet. Diabetes 52:2503-2512

24. Klein T, Ling Z, Heimberg H, Madsen OD, Heller RS, Serup P (2003) Nestin is expressed in vascular endothelial cells in the adult human pancreas. J Histochem Cytochem 51:697-706

25. Piper K, Ball SG, Turnpenny LW, Brickwood S, Wilson DI, Hanley NA (2002) Beta-cell differentiation during human development does not rely on nestin-positive precursors: implications for stem cell-derived replacement therapy. Diabetologia 45:1045-1047

26. Lardon J, Rooman I, Bouwens L (2002) Nestin expression in pancreatic stellate cells and angiogenic endothelial cells. Histochem Cell Biol 117:535-540

27. Edlund H (1998) Transcribing pancreas. Diabetes 47:18171823

28. Edlund H (2001) Developmental biology of the pancreas. Diabetes 50 [Suppl 1]:S5-9

29. Jonsson J, Carlsson L, Edlund T, Edlund H (1994) Insulinpromoter-factor 1 is required for pancreas development in mice. Nature 371:606-609

30. Ahlgren U, Jonsson J, Jonsson L, Simu K, Edlund H (1998) beta-cell-specific inactivation of the mouse Ipf1/ Pdx1 gene results in loss of the beta-cell phenotype and maturity onset diabetes. Genes Dev 12:1763-1768

31. Perez-Villamil B, Schwartz PT, Vallejo M (1999) The pancreatic homeodomain transcription factor IDX1/IPF1 is expressed in neural cells during brain development. Endocrinology 140:3857-3860

32. Edenfeld G, Pielage J, Klambt C (2002) Cell lineage specification in the nervous system. Curr Opin Genet Dev 12:473-477

33. Schwartz PT, Perez-Villamil B, Rivera A, Moratalla R, Vallejo M (2000) Pancreatic homeodomain transcription factor IDX1/IPF1 expressed in developing brain regulates somatostatin gene transcription in embryonic neural cells. J Biol Chem 275:19106-19114

34. Sommer L, Ma Q, Anderson DJ (1996) Neurogenins, a novel family of atonal-related bHLH transcription factors, are putative mammalian neuronal determination genes that reveal progenitor cell heterogeneity in the developing CNS and PNS. Mol Cell Neurosci 8:221-241

35. Lee J, Wu Y, Qi Y et al. (2003) Neurogenin3 participates in gliogenesis in the developing vertebrate spinal cord. Dev Biol 253:84-98

36. Herrera PL (2000) Adult insulin- and glucagon-producing cells differentiate from two independent cell lineages. Development 127:2317-2322

37. Gu G, Dubauskaite J, Melton DA (2002) Direct evidence for the pancreatic lineage: NGN3+ cells are islet progeni- tors and are distinct from duct progenitors. Development 129:2447-2457

38. Park CR (2001) Cognitive effects of insulin in the central nervous system. Neurosci Biobehav Rev 25:311-323

39. De Pablo F, Roth J, Hernandez E, Pruss RM (1982) Insulin is present in chicken eggs and early chick embryos. Endocrinology 111:1909-1916

40. Perez-Villamil B, Rosa EJ de la, Morales AV, Pablo F de (1994) Developmentally regulated expression of the preproinsulin gene in the chicken embryo during gastrulation and neurulation. Endocrinology 135:2342-2350

41. Devaskar SU, Singh BS, Carnaghi LR, Rajakumar PA, Giddings SJ (1993) Insulin II gene expression in rat central nervous system. Regul Pept 48:55-63

42. Devaskar SU, Sadiq HF, Holtzclaw L, George M (1993) The developmental pattern of rabbit brain insulin and insulin-like growth factor receptor expression. Brain Res 605:101-109

43. Molinete M, Irminger JC, Tooze SA, Halban PA (2000) Trafficking/sorting and granule biogenesis in the beta-cell. Semin Cell Dev Biol 11:243-251

44. Alarcon C, Serna J, Perez-Villamil B, de Pablo F (1998) Synthesis and differentially regulated processing of proinsulin in developing chick pancreas, liver and neuroretina. FEBS Lett 436:361-366

45. Hernandez-Sanchez C, Rubio E, Serna J, Rosa EJ de la, Pablo F de (2002) Unprocessed proinsulin promotes cell survival during neurulation in the chick embryo. Diabetes 51:770-777

46. Devaskar SU, Giddings SJ, Rajakumar PA, Carnaghi LR, Menon RK, Zahm DS (1994) Insulin gene expression and insulin synthesis in mammalian neuronal cells. J Biol Chem 269:8445-8454

47. Deltour L, Leduque P, Blume N et al. (1993) Differential expression of the two nonallelic proinsulin genes in the developing mouse embryo. Proc Natl Acad Sci USA 90:527-531

48. Laimins L, Holmgren-Konig M, Khoury G (1986) Transcriptional "silencer" element in rat repetitive sequences associated with the rat insulin 1 gene locus. Proc Natl Acad Sci USA 83:3151-3155

49. Nakamura T, Kishi A, Nishio Y et al. (2001) Insulin production in a neuroectodermal tumor that expresses islet factor-1, but not pancreatic-duodenal homeobox 1. J Clin Endocrinol Metab 86:1795-1800

50. Ahlgren U, Jonsson J, Edlund H (1996) The morphogenesis of the pancreatic mesenchyme is uncoupled from that of the pancreatic epithelium in IPF1/PDX1-deficient mice. Development 122:1409-1416

51. Skene JH (1989) Axonal growth-associated proteins. Annu Rev Neurosci 12:127-156

52. Rulifson EJ, Kim SK, Nusse R (2002) Ablation of insulinproducing neurons in flies: growth and diabetic phenotypes. Science 296:1118-1120 